\title{
Role of Platelet Rich Plasma in Management of Diabetic Wound in Ischemic Lower Limb (after revascularization)
}

\author{
Hossam Ahmed Abo EL Einen, Ayman Refaat Abd-EL Haseeb, Ibrahim Sayed Abd-EL Aziz, \\ Ahmed Massoud
}

General and Vascular surgery department, Faculty of Medicine, Beni-Suef University, Egypt

\begin{abstract}
The aim of this work is detection of the effect of PRP on wound healing on diabetic wound in ischemic patients, this study is randomized controlled clinical trial that was conducted on ( 30 ) patients who was divided in 2 groups; group (A) received PRP, and group (B) received the traditional dressing after revascularization of the previous ischemic diabetic limbs, both groups were divided randomly by randomization block at the department of Vascular and General surgery, Beni - Suef University Hospital. Results: There was no significant association between the both groups regarding the post-operative complication ( $\mathrm{p}$ value; 0.698). There was significant strong inverted correlation between rate of healing and size of ulcers. And there was significant strong proportional correlation between size of ulcers and treatment time $(p=0.002)$ and there was significant strong proportional correlation between size of ulcers and the number of injections $(p=0.040)$. However, the cost of the PRP technique was much higher than the traditional technique and $\mathrm{p}$ value was statistically significant.
\end{abstract}

Keywords: PRP, Wound healing, CLI, Diabetics, Revascularization.

\section{Introduction}

Diabetes mellitus is a metabolic disease characterized by hyperglycemia resulting from defects in insulin secretion, insulin action or both. The chronic hyperglycemia of diabetes is associated with long term damage, dysfunction, and failure of various organs [1]
Currently, the $6.4 \%$ of the world population suffer from diabetes and this percentage is bound to grow and expected to be close to 7.5$8 \%$ in 2030 [2]. Chronic foot wounds are difficult to treat also because of the impaired blood flow and the superimposed infection. Classical treatments are ulcer debridement, 
wound cleaning and coverage with suppress cytokine release and limit compressive or non compressive bandages [3]. inflammation, interacting with macrophages to Due to lack of oxygen, nutrients, and epithelial cells the wound cannot express essential factors for healing. Hence, the treatment of diabetic foot ulcers (DFUs) remains as a challenge. The presence of macro vascular disease, possibly functional micro angiopathy, and infection increase the probability of a foot ulcer leading to a lower-limb amputation [4]. Wound healing is a complex and dynamic process. Once a wound begins healing, normally the process resolves with complete wound closure. However, healing of acute and chronic wounds can become impaired by patient factors (i.e. comorbidities) and/or wound factors (i.e. infection). Chronic wounds include pressure ulcers, venous leg ulcers, arterial ulcers, neurotrophic ulcers, and foot ulcers in people with diabetes [5]. Plateletrich plasma (PRP) is the fraction of plasma having a platelet concentration above baseline; found that proliferation reached a maximum using PRP at a concentration of about $1.25 \times 10^{6}$ $\mathrm{plt} / \mathrm{mL}$ while a concentration of $1.5 \times 10^{6} \mathrm{plt} / \mathrm{mL}$ was most efficient in stimulating the processes of migration and invasion. Platelets initiates wound repair by releasing locally acting growth factors via $\alpha$ - granules [6]. These growth factors aid healing by attracting undifferentiated cells in the newly formed matrix and triggering cell division. PRP may improve tissue healing and regeneration [7]. The growth factors are also important in angiogenesis, cell proliferation and extra cellular matrix synthesis during the healing process. In addition to wound healing the PRP induce hemostasis, antibacterial protection for the wound anti-inflammatory and analgesic effect. Various studies had proved that the use of PRP is safe and cost effective method for wound management [8]. The problem of postoperative wound infection, necessitating weeks of intensive care occurs commonly (i.e., 10 to $30 \%$ ), but rarely is mentioned Interestingly, as seen in distal angioplasty, the patency rates of surgical bypass grafts may lag behind the limb salvage rates. Similar to restenosis, graft closure after wound healing may not always lead to significant ischemia [9]. Primary minor Amputation in the critically ischemic limb as a first line therapy carries high risk for major amputation, $2^{\text {nd }}$ amputation frequently necessary, disability (In the elderly, who are most at risk, the probability of loss of independence and reduced quality of life from an amputation is significant [10]. Currently it appears that whatever treatment successfully prevents major amputation will be cost effective, with benefit to the individual as well as society).Conservative management with or without Sympathectomy is of unproven 
benefit. [11]. It is important to remember that PRP is an autologous biomaterial and its "quality" is directly related to the biological conditions of the donor source. The variability of results may be related to general clinical conditions of the patient. A careful assessment of the mechanical and biological factors involved in the process of the lesion should be carried out in order to direct the treatment and guide a precise technical indication. In addition, PRP results are greatly influenced by procedures normally associated with treatment, such as surgical interventions, the use of grafts, physical therapy and medication. Thus, the importance of baseline studies to broaden researchers' understanding of the action of each growth factor in the healing cascade is similar to the importance of clinical trials with high levels of scientific evidence, since they clarify the potential of the PRP technique in light of the complexity of the human body. A set of good quality basic and clinical studies will determine the guidelines for establishing the necessary criteria for PRP use in Regenerative Medicine. [11]. Researchers have since been concerned with organizing the great variety of extant terms and products according to their characteristics and applications. From blood collection to the moment of application, different PRP preparation protocols have resulted in the production of several types of concentrates. The following are among the main variations: - the occurrence of trauma at the moment of blood collection, which risks platelet degranulation before PRP preparation; • the methods of preparation: (1) manually, in a unidirectional flow chamber, (2) using kits that facilitate separation of the different blood components, and (3) by apheresis, with pure PRP being separated from the blood as it is collected and the unused blood fraction reinfused in the patient; $\bullet$ the amount, speed and time of centrifugation, which determines the quantity of concentrated platelets and influences their capacity to aggregate in the final product; - the presence or absence of leukocytes; - the use or not of different types of anticoagulants, such as citrate dextrose, sodium citrate and heparin; $\bullet$ the use or not of agonists or platelet activators, such as calcium chloride, adenosine di phosphate (ADP), a epinephrine, collagen and thrombin (the most powerful of them); - the characteristics of the fibrin mesh; - the origin of the blood used, either autologous or from blood banks and blood centers, according to $\mathrm{ABO}$ and $\mathrm{RH}$ compatibility[12]. Being considered an autologous biomaterial, PRP also varies according to the biological conditions of the patient, such as age, gender ,associated diseases, hormone disorders, blood dyscrasias, amount of endogenous cortisol and IGF-1 and the use of anti inflammatory medications, acetylsalicylic acid, antibiotics and several 
other classes of medication that influence platelet degranulation. All of these variations alter in some way the final number of platelets and their action on injuries with 3 to 27 fold variations possible in the concentration of growth factors and release kinetics [13]. Reports of failures may be explained by this wide variation in available products. Furthermore, the factors are practically all released in the first hour after inducing platelet aggregation [14] and have low stability in vivo [15]. A recent study reports that the process of progressive activation of leukocyte free PRP exceeds that of the platelet concentrates with leukocytes [16]. This shows the growing need to characterize the different products and understand their activity in different tissues in order to guide their application [17]. A number of studies have shown the different roles of each agent in PRP and the healing process chain, even though the published information is still either insufficient or based on case studies or on data obtained from animals and studies in vitro [17].

\section{Patients and Methods}

This study is randomized controlled clinical trial that was conducted on (30) patients who was divided in 2 groups; group (A) received PRP, and group (B) received the traditional dressing after revascularization of the previous ischemic diabetic limbs, both groups was divided randomly by randomization block at the department of Vascular and General surgery, Beni - Suef University Hospital written consents were obtained.

\subsection{Inclusion criteria:}

1. Diabetic patients who have wounds in ischemic lower limbs after revascularization.

\section{Exclusion criteria:}

1. Patients younger than 30 or older than 75 years old.

2. Uncontrolled hyperglycemia (hemoglobin Alc $>9 \%)$.

3. Serum albumin less than $2.5 \mathrm{gm} / \mathrm{dl}$.

4. Anemia (hemoglobin $<8.0 \mathrm{~g} / \mathrm{dl}$ ).

5. Thrombocytopenia (platelets $<10^{5} / \mathrm{mm} 3$ ).

\subsection{All patients were subjected to:}

Pre injection evaluation: An informed consent and all patients history was taken, physical examination, Doppler ultrasound and C.T. angiography scan of the leg and X-ray of the foot. Basic laboratory investigations including blood glucose level, blood picture, serum creatinine, liver function tests, coagulation profile and serum albumin.

\section{Treatment protocol:}

Treatments was done after the diagnosis of the diabetic limb ischemia was confirmed, and the management in the form of bypass surgery or endovascular revascularization was done, an initial excision and or debridement was done followed by baseline wound measurements and 
evaluation and follow-up the patients for six months.

\section{Preparation of PRP}

$20 \mathrm{ml}$ of venous blood was collected from all patients using a sterile $20 \mathrm{~mL}$ syringe, each blood sample was transferred to a sterile tube or a tube with gel-filtration barrier containing adenosine-citrate dextrose acid (ACD-A) solution (1 part of citrate to 9 parts of whole blood) to prevent clotting. Then each blood sample was centrifuged at room temperature at $1500 \mathrm{rpm}$ for $5 \mathrm{~min}$ to obtain plasma. Then, this plasma was collected using a sterile pipette and transferred to another sterile tube and centrifuged at $3500 \mathrm{rpm}$ for $5 \mathrm{~min}$. The platelet rich plasma (PRP) separated at the bottom of the tube was collected using a sterile pipette. 3 $\mathrm{ml}$ out of $6 \mathrm{ml}$ of PRP was kept in a sterile syringe for local injection in the wound. Then $3 \mathrm{ml}$ of PRP from each group was activated to release growth factors by addition of $0.3 \mathrm{~mL}$ of a $10 \%$ calcium chloride solution.

\section{Statistical methodology}

Data were analyzed using SPSS 18 (Statistical Package for Scientific Studies) for Windows Data were explored for normality using Kolmogorov-Smirnov test of normality and levene test for homogeneity of variance The results of Kolmogorov-Smirnov test and levene test indicated that some data were normally distributed (parametric data) so parametric tests were used for comparisons.
The significance of the results was assessed in the form of

$\mathrm{P}$-value that was differentiated into:

- Non-significant when P-value $>0.05$

- Significant when P-value $\leq 0.05$

- Highly significant when P-value $\leq 0.01$.

\section{Results}

This was a longitudinal study during which (30) patients were enrolled. The median age was $59.63 \pm 7.08$, range 23 (min. 48 and $\max 71$ yrs.) The gender distribution was $12(40 \%)$ female and $18(60 \%)$ male. A number of $24(80 \%)$ of the patient participants underwent endovascular revascularization while only $6(20 \%)$ Patients underwent open revascularization. Those who have only one comorbidity were 8 (26.7) while the majority of participants were having more than one comorbidity 22(73.3\%). The participants were randomly divided into two groups. A number of 15 patients used PRP as a mode of dressing and the other 15 patients used the traditional methods. There is no significant association between the both groups regarding the post-operative complication ( $p$ value $=0.698$ ). There is significant strong inverted correlation between rate of healing and size of ulcers. And there is significant strong proportional correlation between size of ulcers and treatment time $(p=0.002)$ and there is significant strong proportional correlation between size of ulcers and the number of injections $(\mathrm{p}=0.040)$. However, the cost of the PRP technique was much 
higher than the traditional technique and $\mathrm{p}$ value

was statistically significant (0.001).

Table (1): Comparison between age, site and size of ulcer in the two studied groups.

\begin{tabular}{|c|c|c|c|c|c|c|}
\hline Variable & $\mathrm{N}$ & Range & Minimum & Maximum & Mean & Std. Deviation \\
\hline Age & 30 & 23.00 & 48.00 & 71.00 & 59.6333 & 7.08803 \\
\hline Site, size of ulcer & 30 & 6 & 2 & 8 & 3.30 & 1.705 \\
\hline
\end{tabular}

Table (2): Types of revascularization

\begin{tabular}{|c|c|c|}
\hline Type of revascularization & Frequency & Percent \\
\hline Endovascular angioplasty & 24 & 80.0 \\
\hline Open surgical intervention & 6 & 20.0 \\
\hline
\end{tabular}

TYPE OF REVASULARIZATION

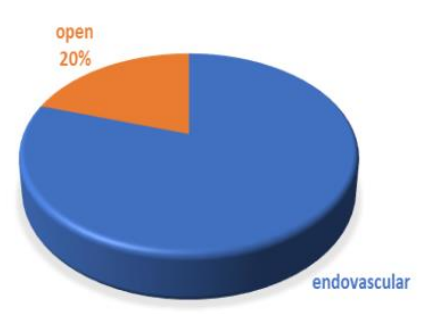

$80 \%$

Figure (1): Types of revascularization

Table (3), figure (2): variable sites of ulcers and frequency in each site in all studied cases

\begin{tabular}{|c|c|c|}
\hline Type of wound, pre-injection preparation & Frequency & Percent \\
\hline Heel & 3 & 10.0 \\
\hline Fore foot & 9 & 30.0 \\
\hline 2nd toe & 10 & 33.3 \\
\hline Big toe & 5 & 16.7 \\
\hline Little toe & 3 & 10.0 \\
\hline Total & 30 & 100.0 \\
\hline
\end{tabular}

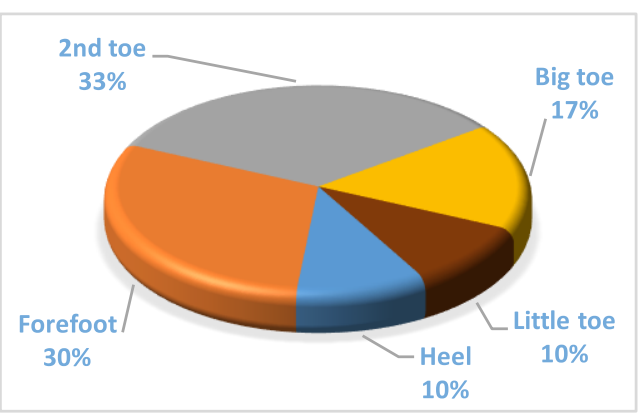




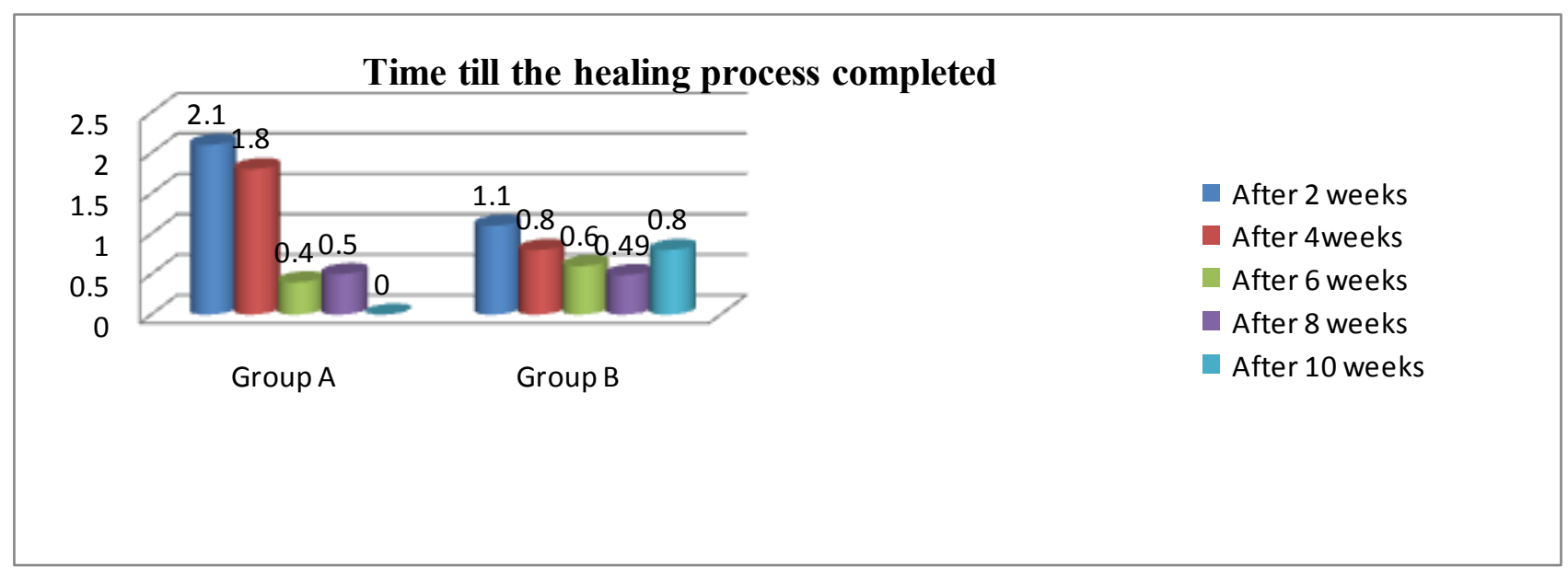

\section{Discussion}

Preterm birth is among the top causes of death in infant's worldwide [1]. It is estimated that more than one million children in the world die every year because of preterm birth [2]. Preterm birth (PTB), or delivery before 37 weeks, occurred in $11.7 \%$ of births in the U.S. in 2011 and accounted for $85 \%$ of perinatal mortality and morbidity [4]. Successful PTB prevention has been demonstrated with the use of progesterone prophylaxis in selected highrisk pregnancies [4]. Natural progesterone is free of any disturbing teratogenic, metabolic, or hemodynamic effects. This is not true for certain synthetic gestagens and $\beta$ mimetic [15]. Dihydropyridine $\mathrm{Ca}^{+2}$ channel blockers (CCBs) are widely accepted in the treatment of premature labor. In clinical practice, most experience has been gained with the use of Nifedipine, whose efficacy is superior or comparable to those of $\beta$-agonists and oxytocin receptors antagonists [18].
The current study aimed at comparing effectiveness of progesterone with nifedipine therapy in prevention of preterm labor. The study included 70 pregnant women selected on basis of previous one or more preterm labor, singleton pregnancy and at gestational age less than 24 weeks. We excluded antepartum ROM, cervical incompetence, cerclage, congenital fetal malformations, hypertension or any other medical disorders and progesterone allergy.

In our study, distribution of the studied group as regards general data. Average age was (26.1 yr), range of age was (19-36), average of BMI $\left(19.8 \mathrm{~kg} / \mathrm{m}^{2}\right)$, range was (13.2-31.1) and average of parity (3), range was (1-5).as showed in table (1) and (2). There was no significant difference between both groups as regards age, parity, body mass index, number of previous preterm labor and occupation of women. These results agreed with the studies of [21-25]. 
The success rate of prevention of preterm labor was $(88.6 \%)$ in the progesterone group and $(80 \%)$ in the CCBs group and the difference was non-significant. This agreed with the results of [21] study, the success rate was $82.7 \%$ with progesterone and $78.7 \%$ with nifedipine. There was no significant difference between both groups. This agreed with the results of [22] study, the success rate was $66 \%$ (33/50) with progesterone and 80\% (40/50) with nifedipine. There was no significant difference between both groups. This did not agree with [23]. There was no significant difference between both groups as regards the gestational age at the time of delivery, where in the progesterone group mean was $(38 \pm 1.7))$ while in the nifedipine group it was $(37.6 \pm 2)$. These findings are in agreement with [21] who reported that mean gestational age at delivery in the progesterone group was $(37.5 \pm 3)$ while in nifedipine group it was $(37.6 \pm 4)$.

Also agreed with results of [22] study, where in progesterone group the mean was $(36.3 \pm 2.1)$ but in nifedipine group it was (36.9 $\pm 1.7)$. These findings were not in agreement with [24] who reported that mean gestational age at delivery in the progesterone group was $(37 \pm 2.8)$ weeks versus $(36 \pm 3.3)$ weeks in the placebo group. While the average gestational age for those who had preterm birth was $(33.5 \pm$ 2.4) weeks in the progesterone group while (32 \pm 0.7 ) weeks in the placebo group. The difference is significant. There was no significant difference between both groups as regards fetal birth weight, mean fetal birth weight in Progesterone group was $(2.9 \pm 0.5)$, but in nifedipine group, it was $(2.9 \pm 0.5), p$ value (0.980).

These findings were in agreement with [23] who reported that the mean fetal birth weight in Progesterone group was $(2.679 \pm 0.455)$, while in nifedipine group, it was $(2.547 \pm 0.253), \mathrm{p}$ value (0.56). Also, these agreed with [25] who reported that the mean fetal birth weight in placebo group was $(2.781 \pm 0.444)$, while in 17 OHP group it was $(2.903 \pm 0.592) \mathrm{p}$ value (0.372). The difference was no significant.

However, these findings were not in agreement with [26] who reported that the average of fetal birth weight in placebo group was $(2.609 \mathrm{~kg})$ and in Progesterone group was $(3.101 \mathrm{~kg})$. The difference is significant. The difference in fetal birth weight at delivery between the current study and the others may be due to the use of placebo in other studies and number of patients of each study.

Regarding the side effects of our studied drugs, the nifedipine group had more side effects than the Progesterone group. $\mathrm{P}$ value (0.018), this showed significant difference between both groups. Regarding the occurrence of significant uterine contractions there was no significant difference between the both groups, $\mathrm{p}$ value (0.077). In Progesterone group uterine 
contractions occurred in (8/35) $(22.9 \%)$. In nifedipine group, uterine contractions occurred in $(16 / 35)(45.7 \%)$.

These findings were the same as the results of [28] who reported that percentage of recurrence in the Progesterone group was (35.1 $\%)$ versus $(57.6 \%)$ in control group. P value (0.092) there was no significant difference.

These findings were not the same as those in [21] study who reported that there was significant difference between the both groups as regarding the occurrence of significant uterine contractions, $\mathrm{p}$ value (0.035). The difference in occurrence of uterine contractions between the current study and the others may be due to the difference in number of the studied groups and the presence of threatened preterm labor.

The study showed that progesterone and nifedipine were associated with a reduction in the risk of preterm birth and infant birth weight of less than $2500 \mathrm{gm}$ in the patients who had previous history of the preterm birth. Therefore, natural progesterone and nifedipine were still the promising medication to use in prevention of preterm labor with minimal side effects.

\section{Conclusion and Recommendations}

Prophylactic use of nifedipine was effective as vaginal progesterone in reducing the rate of preterm labor, prolongs gestational age at delivery, and reduces the frequency of uterine contractions in women with previous history of preterm labor. The study recommends using nifedipine and vaginal progesterone in prevention of preterm labor.

\section{References}

1- Blencowe H, Cousens S, Oestergaard M, Chou D, Moller AB, Narwal R, Adler A, Garcia CV, Rohde S, Say L, Lawn JE. National, regional and worldwide estimates of preterm birth. Lancet, 2012; 379(9832): 2162-72.

2- Tan MY and To M. Recent advances in the prevention and management of preterm birth 2015; 7(40): 1-7.

3- American College of Obstetricians and Gynecologists (ACOG Practice Bulletin): Assessment of risk factors for preterm birth. Clinical management guidelines for obstetrician-gynecologists. Obstet Gynecol. 2014; 98(4s):709-16.

4- Norwitz ER. Progesterone supplementation to reduce the risk of spontaneous preterm birth. In: UpToDate, Basow, DS (Ed), UpToDate, Waltham, MA, 2013.

5- Jayanta C, Joanna G, Manu V, Steve T. The management of preterm Labor. Arch Dis. Child. Fetal Neonatal Ed. 2007; 92(2): F88F93.

6- Goldenberg RL. The Management of Preterm Labor. Obstetrics \& Gynecology, 2011; (7): 787-791 
7- Fuchs AR. Fuchs F. Endocrinology of human parturition: a review. $\mathrm{Br} J$ Obestet gynaecol. 1984; 91(10):948-67

8- Newman RP, Campbell BA, Stramm SL. Objective tocodynamometry identifies labor onset earlier than subjective maternal perception. Obstet. Gynecol. 1990; 76(6):1089-92.

9- Noblot G, Audra P, Dargent D, Faguer B, Mellier G. The use of micronized progesterone in the treatment of preterm delivery. Euro. J. Obstet. Gynecol. 1991; 40(3): 203-9.

10-Liong S, Di Quinzio MK, Fleming G, Permezel M, Rice GE, Georgiou HM. New biomarkers for the prediction of spontaneous preterm labor in symptomatic pregnant women: a comparison with fetal fibronectin. BJOG, 2014; 122(3): 370-9.

11- Lifshitz SJ, Razavi A, Bibbo C, Rebarber A, Roman AS, Saltzman DH, Fox NS. Routine cervical length and fetal fibronectin screening in asymptomatic twin pregnancies: is there 23 clinical benefits? $J$ Matern Fetal Neonatal Med. 2014; 27(6): 566-70.

12-Kerenyi T. Forgotten "father of progesterone". Am J Obstet Gynecol. 2010; 202(6): e10-1

13-Norwitz ER, Mahendroo M, Lye SJ. Biology of parturition. In: Creasy RK, Resnik R, Iams JD, Lockwood CJ, Moore
TR, Greene MF, eds. Creasy and Resnik's maternal fetal medicine: principles and practice. 7 th ed. Philadelphia: Saunders/Elsevier, 2013:66-79.

14- Norman JE, Yuan M, Anderson L, Howie F, Harold G, Young A, Jordan F, McInnes I, Harnett MM. Effect of prolonged in vivo administration of progesterone in pregnancy on myometrial gene expression, peripheral blood leukocyte activation, and circulating steroid hormone levels. Reprod Sci. 2011; 18(5): 435-46.

15-Keelan, J, Myatt L, Mitchell M. Endocrinology and paracrinology of parturition. in: MG Elder, LR Romero (Eds.) Preterm labour. Churchill Livingstone, London; 1997:457-491.

16- Hassan SS, Romero R, Vidyadhari D, Fusey S, Baxter JK, Khandelwal M, et al. Vaginal progesterone reduces the rate of preterm birth in women with a sonographic short cervix: Ultrasound. Obstet Gynecol. 2011; 38(1):18-31.

17-Likis FE, Andrews JC, Woodworth AL, Edwards DRV, Jerome RN, Fonnesbeck CJ, et al. Progestogens for prevention of preterm birth. Comparative Effectiveness Review No.74. 2012.

18-Gáspár R, Hajagos-Tóth J. Calcium channel blockers as tocolytics: principles of their actions, adverse effects and therapeutic 
combinations. Pharmaceuticals (Basel). 2013; 6(6): 689-699.

19-Royal College of Obstetricians and Gynaecologists (RCOG, 2011): Women most likely to benefit from use of a tocolytic drug. RCOG green-top guideline No. $1 \mathrm{~b} ; 2$ of 13.

20-Knapp RG, Miller MC. Clinical epidemiology and biostatistics. Published by Williams \&Wilkins; Malvern Pa, Harwal Pub. Co., C.

21-Rabei N, Osama M, Sultan A. Comparison of the efficacy of progesterone and nifedipine in inhibiting threatened preterm labor: A randomized study. International Journal of Obstetrics and Gynaecology Research (IJOGR), (2016); 3(5):56-367.

22-Chawanpaiboon S, Pimol K, Sirisomboon R. Comparison of success rate of nifedipine, progesterone and bed rest for inhibiting uterine contractions in threatened preterm labor. J. Obstet Gynecol. Res. 2011; 37(7): 787-91.

23- Da Fonseca EB, Bittar RE, Carvalho MH, Zugaib M. Prophylactic administration of progesterone by vaginal suppository to reduce the incidence of spontaneous preterm birth in women at increased risk: a randomized, placebo-controlled, doubleblind study. Am J Obstet Gynecol. 2003; 188(2): 419-24.

24-Regmi MC, Rijal P, Agrawal A, Uprety D. Progesterone for prevention of recurrent preterm labor after arrested preterm labor. A randomized controlled trial. Gynecol Obstet. $2012 ; 2: 125$.

25-Borna S, Sahabi N. Progesterone for maintenance tocolytic therapy after threatened preterm labor: a randomized controlled trial. Aust N Z J Obstet Gynaecol. 2008; 48(1): 58-63. 